\title{
Sequential Green Extraction of Caffeine and Catechins from Green Tea
}

\author{
Gönül Serdar (iD)*1, Ezgi Demir ${ }^{2}$, Münevver Sökmen (iD)3
}

\begin{abstract}
${ }^{1}$ Department of Central Research Laboratory, Karadeniz Technical University, Trabzon, Turkey
${ }^{2}$ Department of Plant Sciences, Faculty of Agriculture and Natural Sciences, Konya Food and Agriculture University, Konya, Turkey

${ }^{3}$ Department of Bioengineering, Faculty of Engineering and Arhitecture, Konya Food and Agriculture University, Konya, Turkey
\end{abstract}

\begin{abstract}
Separation of caffeine and catechins from tea extracts usually requires conventional liquid-liquid extraction employing chloroform. This work was planned to improve a green extraction technique to distunguish these important chemicals from green tea. Extraction of caffeine and catechins from Turkish green tea firstly employing MAE, and then to separate these compounds from each other using a SFE method were purpose of this study. Microwave assisted extraction was applied to extract tea components from green tea then $i$ ) conventional liquid-liquid extraction or ii) supercritical carbon dioxide fluid extraction (SFE) method was charged with the effective separation of caffeine and catechins. Initially, an ethanol: water mixture was used in a close microwave system under the particuler extraction situations of green tea samples (fresh, frozen or dried) picked up in three collection periods (first, second and third collection periods). MAE of tea samples was exerted under a controlled $600 \mathrm{~W}$ microwave power for $4 \mathrm{~min}$ irradiation time at $80{ }^{\circ} \mathrm{C}$ temperature. Then MAE crude aqueous extract was divided in to two portions. The first portion was fractionated first with chloroform to distunguish caffeine then ethyl acetate for catechins. Caffeine and catechins were successfully separated. Second portion was freeze-dried and obtained lyophilized solid was used for SFE. Caffeine (3.68\% extract yield) was successfully separated from catechins with SFE at 250 bar and $60^{\circ} \mathrm{C}$ for $180 \mathrm{~min}$. Constituents of the extracts were determined (caffeine and four catechins namely EGC, EC, C, EGCG) by HPLC to evaluate the effectiveness of the separation.
\end{abstract}

\section{ARTICLE HISTORY}

Received: February 11, 2019

Revised: August 11, 2019

Accepted: September 25, 2019

\section{KEYWORDS}

Caffeine,

Catechins,

Supercritical Fluid Extraction (SFE),

Microwave Assisted Extraction (MAE),

Green Tea

\section{INTRODUCTION}

Green tea has been popular beverage in Asian countries and is consumed all over the World [1]. Green tea is made ready through processing of tea leaves without fermentation [1]. The components of green tea include $10-30 \%(\mathrm{w} / \mathrm{w})$ polyphenols, $2-4 \%(\mathrm{w} / \mathrm{w})$ caffeine [2], aroma chemical, fats, vitamins, amino acids, chlorophyll, others [3]. The strain of tea tree, manufacturing process employed, harvest time varies according to ingredient of green tea $[4,5]$. Catechines, flavanols, flavanonens, phenolic acids, plant pigments and glycosides are which

CONTACT: Gönül SERDAR $₫$ gonulserdar@ktu.edu.tr Department of Pharmacy, Faculty of Science, Karadeniz Technical University, Trabzon, TURKEY 
polyphenols of tea [6]. This group of compounds is known to preserve good bioactive effects incluiding anticancer, antioxidation, antimutagenic properties of tea [7,8]. Investigators embarked on enterprise selectively extraction of caffeine and catechins from green tea by various methods.

Chloroform, isopropanol, ethyl acetate and methylene chloride have been effectively used to remove caffeine and to produce decaffeinated green tea [9]. Vuong and Roach [9] have been investigated alternative studies because the use of organic solvents increases health problems in food processing. Chloroform and ethyl acetate are used but not approved resulting from their toxicities in spite of they are effective [10]. Green extraction techniques has important advantages than traditional methods such as greater energy efficiency, shorter extraction time, less solvent and reduction of environmental pollution [11]. Microwave-assisted extraction, carbon dioxide supercritical fluid extraction, ultrasonic-assisted extraction have progressed in recent years owing to its inherent advantages such as solvent volume, reduction in extraction time over more conventional extraction techniques. MAE is novel technique that utilizes nontoxic solvents, microwave energy to extract objective compounds from different matrices and also provides an important reduction in the depletion of organic solvents for extraction. And then MAE is extracting soluble products into a fluid from a wide variety of materials utilizing microwave energy. Microwaves increase speed of heating by directly heating solvent or solvent mixture $[12,13]$. Pressure, extraction time, co-solvent, moisture content of tea leaf and temperature affect to SFE selectivity [14-16]. SFE utilising $\mathrm{CO}_{2}$ as a solvent can be option to toxic organic solvents. Generally, carbon dioxide is utilised as a supercritical fluid owing to it has low critical temperature and pressure [17]. $\mathrm{CO}_{2}$ is a non-toxic, nonflammable, environmentally-friendly, quite inexpensive, easily separated from the system and do not leave waste. SFE is a fast, leaves no toxic residue and provides less degradation of catechins [9]. Vuong and Roach [9] have been planned in line with the increasing needs for the development of safe, sustainable and environmentally friendly methods to separate caffeine and catechin from green tea in their study. Bimakr [18] and Park [14] found and the optimum condition of SFE was achieved at $200 \mathrm{bar}, 60{ }^{\circ} \mathrm{C}$ and $60 \mathrm{~min}(60.566 \mathrm{mg} / \mathrm{g}$ extraction yield). Maran [19] advanced SFE method appropriate for extraction of phenolic compounds from tea leaves at differant extraction conditions. And so, they asserted extraction pressure (100-200 bar), cosolvent flow rate (1-3 g/min) have significant effect. Some reports are available on extraction of catechins from both black tea and green tea in supercritical carbon dioxide with the addition of cosolvents such as ethanol and water [14, 16, 20,21].

MAE is an effective extraction process for green tea which was previously utilised for extraction of various tea samples (dried, fresh or frozen) collected in first, second and third collection periods $[22,23]$. MAE provides a mixture of both caffeine and catechins and another separation step should be employed for effective separation of caffeine from catechins. The purpose of this work is to extract caffeine and catechins from green tea firstly employing MAE, then to separate these compounds from each other using a SFE method. We have employed a conventional liquid-liquid extraction method to separate caffeine and catechins to compare the extraction effectiveness of the developed SFE method.

\section{MATERIAL AND METHODS}

\subsection{Standards and Chemicals}

Chloroform, ethanol and ethyl acetate were analytical grade from Merck. Caffeine, gallic acid, (-) epicatechin, (-) epigallocatechin, (-) epicatechin gallate and (-) epigallocatechin gallate of standard chemicals were bought from Sigma (St Louis, MO, USA). Green tea samples used in the experiments were supplied by a local tea producer (Sürçay San. Co. Ltd., Trabzon, Turkey) in 2016. Green tea samples were collected at three collection periods (first, second and third collection) of the same year and location. After collection tea samples were either 
extracted directly (fresh), extracted after freez drying (freezed) or extracted after drying the sample (dried).

\subsection{Microwave Assisted Extraction}

Initially, tea ingredients were extracted utilizing a close microwave assisted extraction system (MILESTONE, START S Microwave, USA). Extraction time and microwave power from MAE parameters can influence the extraction performance [24]. Extraction conditions were previously reported by our group [22,23]. $10 \mathrm{~g}$ of tea sample and $200 \mathrm{ml}$ ethanol-water $(1: 1 \mathrm{v} / \mathrm{v})$ solution were placed in extraction vessel. Extraction was performed under a controlled at $80{ }^{\circ} \mathrm{C}$ temperature, $600 \mathrm{~W}$ microwave power for $4 \mathrm{~min}$ irradiation time. Aqueous tea infusion was divided into two portions. The first portion was used for liquid-liquid separation and second portion was freeze dried. After drying process the remaining solid vas used for SFE experiments. The same procedure was repeated three times and data was calculated from the results of replicates.

\subsection{Conventional Liquid-liquid Extraction}

After completion of the MAE obtained aqueous tea infusion was filtrated and the filtrates were initially partitioned with chloroform to remove caffeine. A $50 \mathrm{~mL}$ portion of chloroform was used to extract caffeine and this was repeated three times. Then separation of caffeine the aqueous phase was re-extracted with ethyl acetate following the same procedure. The filtrate was concentrated by a rotary evaporator under reduced pressure at $55^{\circ} \mathrm{C}$ after the ethyl acetate and chloroform phases were filtered. Extract yield was calculated according to this formula;

$$
\text { Extract Yield } \%=(\text { mass of extract/mass of tea sample }) \times 100
$$

The yields of caffeine and catechins were calculated after process and purity/combination of the extracts were determined by HPLC.

\subsection{Supercritical Carbondioxide Extraction}

The freeze dried extracts obtained from MAE were subjected to SFE. Aqueous tea infusion was completely dried by freeze drying. Caffeine extraction was carried out with SFE at $60^{\circ} \mathrm{C}, 10-30 \mathrm{MPa}$ for 3 hours $[25,26]$. Then separation of caffeine the remaining solid mainly contains catechins. The extract yield of caffeine was calculated and purity/composition of the extracts were stated by HPLC analyses. Extraction steps are given in Schema 1.

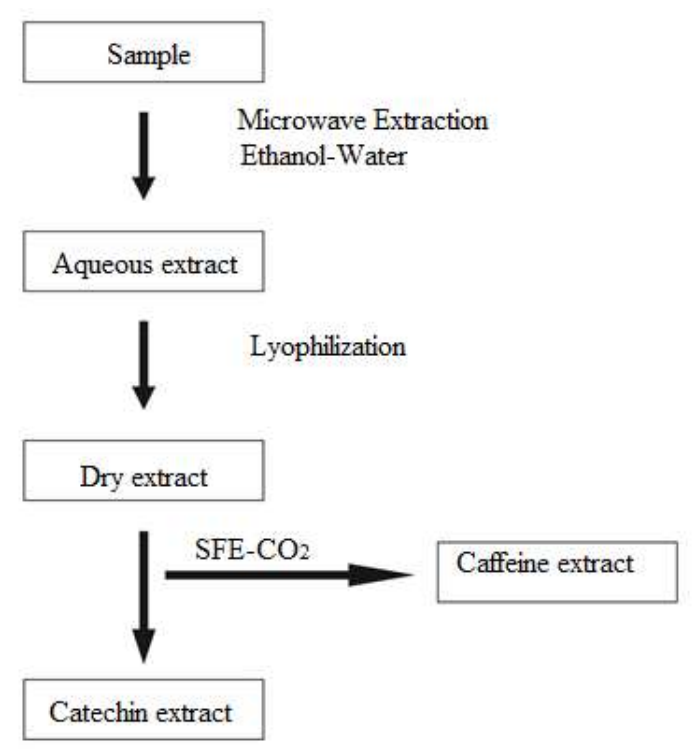

Schema 1. Extraction and separation steps of caffeine and catechins. 


\subsection{Quantification of Caffeine and Catechins}

HPLC analyses were performed to decide the amount of each catechins in the mixture [27] and the purity of distinguished phases. The instruments used in the work was a HPLC system (Hitachi Elite Lachrom) equipped with a Shim-pack VP-ODS C18 column (5 mm, 4.6 x $250 \mathrm{~mm}, 35^{\circ} \mathrm{C}$ ) at $278 \mathrm{~nm}$. Solvents A (water) and B (DMF-methanol-acetic acid mixture, 20:1:0.5) were run with $86 \%$ A for 13 minutes. After that, its volume was decreased to $64 \%$ within next 15 minutes and back to initial concentration for another $6 \mathrm{~min}$. Concentration of each catechin was measured by their peak areas against those of standards made from original compounds.

\section{RESULTS and DISCUSSION}

\subsection{Liquid-liquid Extraction After MAE}

The average caffeine and catechin yields from the first (in May, I. Collection), second (in June, II. Collection) and third collection periods (in August-September, III. Collection) are given in the Figure 1 and Figure 2. Data is the average of three replicates.

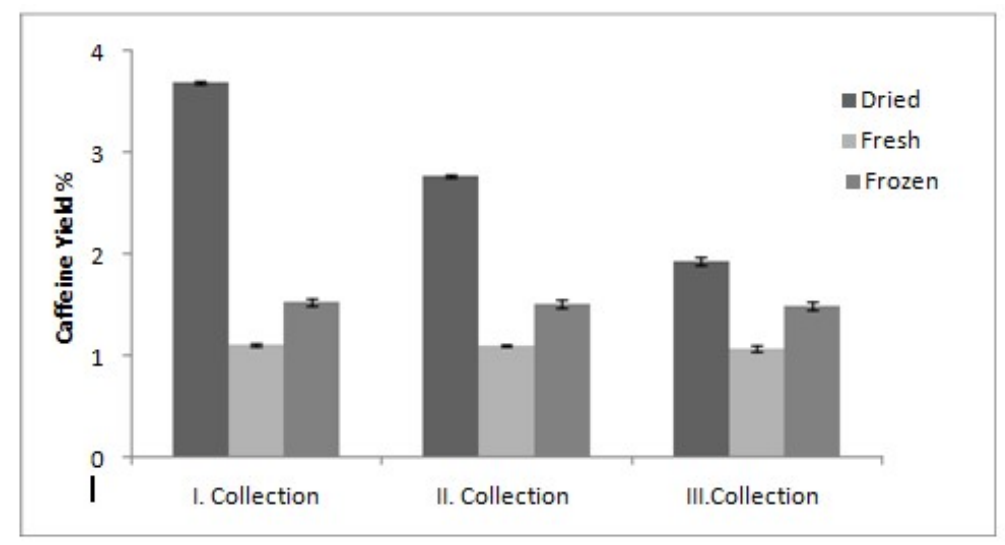

Figure 1. Caffeine content of the dried, fresh and frozen green tea leaves in first, second and third collection periods

Caffeine yields varied between $0.51 \%$ and $3.68 \%$. The highest caffeine extract yields were obtained from the dried sample of the first collection. It is expected since dried samples contain higher amount of biomolecules. Almost 60-70 percent of water content of the tea leaves are lost during drying process. First collection gave higher amount of caffeine.

Catechin extract yields are given in Figure 2. Similarly dried samples of first collection period gave highest extract yield. It is gradually decreased at second and third collection periods. 


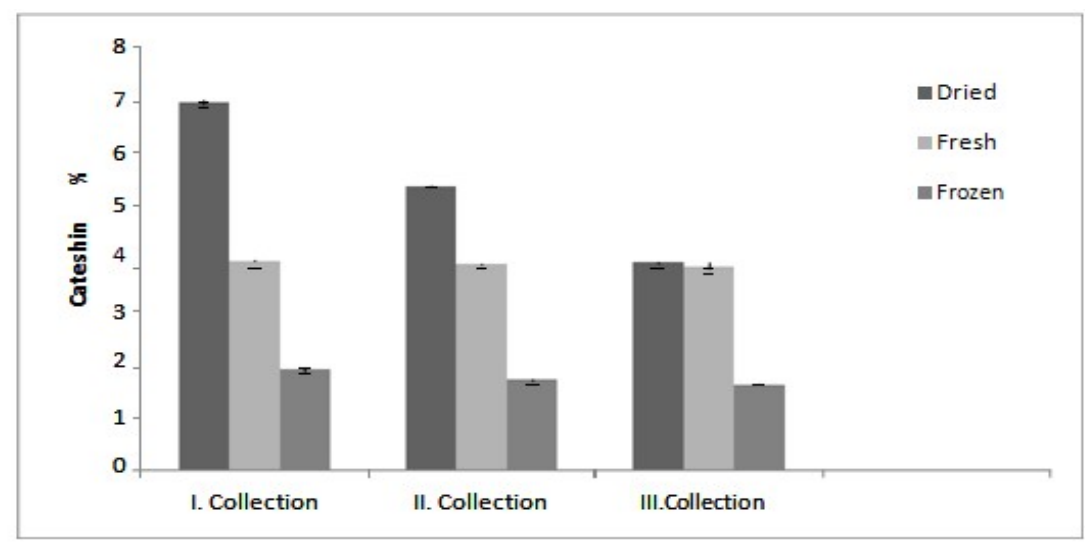

Figure 2. Total catechin content of the dried, fresh and frozen green tea leaves in first, second and third collection periods.

\subsection{Supercritical Carbondioxide Extraction After MAE}

SFE method was tested only for dried tea samples. Caffeine and catechin extraction from tea samples were already optimized by our group [25]. We reported direct supercritical fluid extraction of these compounds from dried green tea. It was an effective method extracting caffeine first running the instrument for 3 hours employing SFE supercritical fluid (25 MPa and $60{ }^{\circ} \mathrm{C}$ ). Additionally, another 3 hours was necessary to extract catechins under the identical situations however, using ethanol as modifier at $0.5 \mathrm{~mL} / \mathrm{min}$ flow rate. So, at least 6 hours extraction period is needed for a successful extraction of these important tea components. However, MAE is achieved in only 4 minutes and separation of caffeine from catechins is fulfilled within 3 hours. Caffeine extract yields obtained with SFE at different pressures are given in Figure 3.

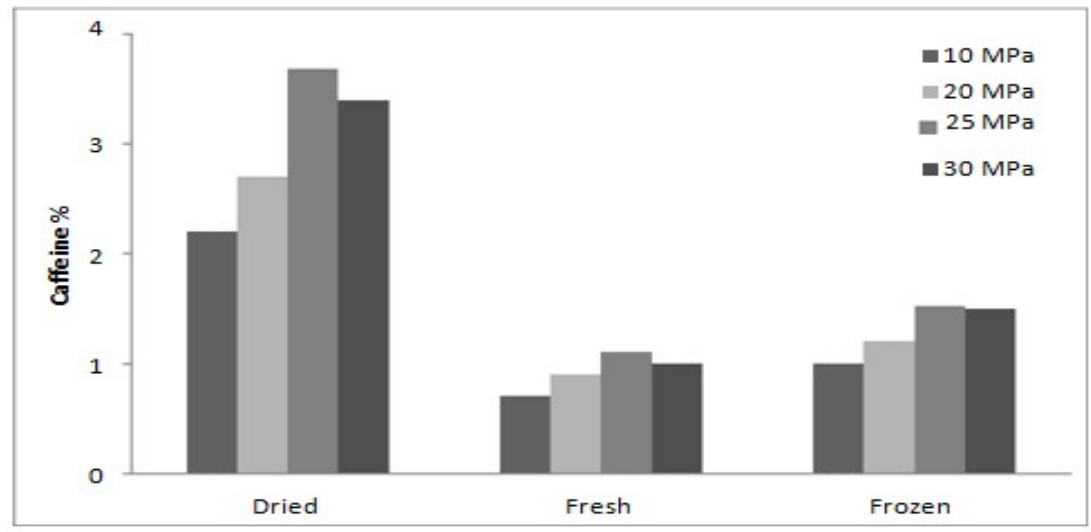

Figure 3. Caffeine yields of the dry, fresh and frozen green tea leaves after MAE (I. Collection period, $60^{\circ} \mathrm{C}$ and $3 \mathrm{~h}$ ).

It is clear that high pressure is required to separate caffeine from the mixture and $25 \mathrm{MPa}$ provide the highest caffeine yield (3.68\%) which is equal to the amount of caffeine separated with liquid-liquid extraction. This is quite strong evidence that SFE is able to separate all caffeine content from the mixture. MAE can be used for total extraction of tea components then following this step SFE might be used as effective green extraction methods for effective separation of caffeine from catechins.

\subsection{HPLC Analysis}

Caffeine and catechin concentrations of the extracts were identified by reversed-phase HPLC. Catechin standards were catechine (C), epicatechin (EC), epigallocatechin (EGC) and epigallocatechin gallate (EGCG). The chromatogram of the standard mixture is given in Figure 4. 


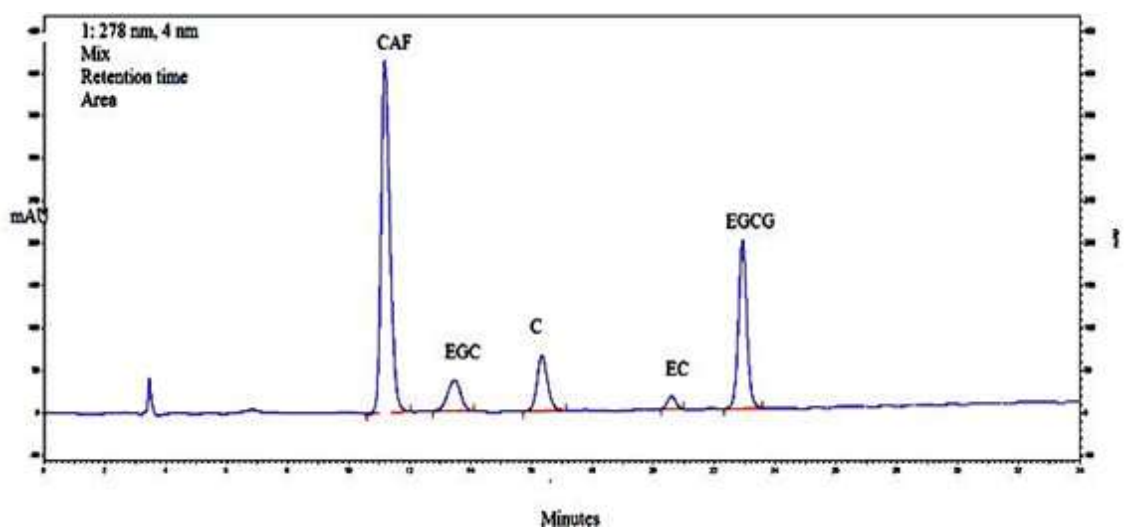

Figure 4. The chromatogram of caffeine and catechin standarts. Retention times are as below; caffeine 11.18; EGC 13.34; C 16.44; EC 20.60; EGCG 22.03 min. Injection volume is $20 \mu \mathrm{L}$.
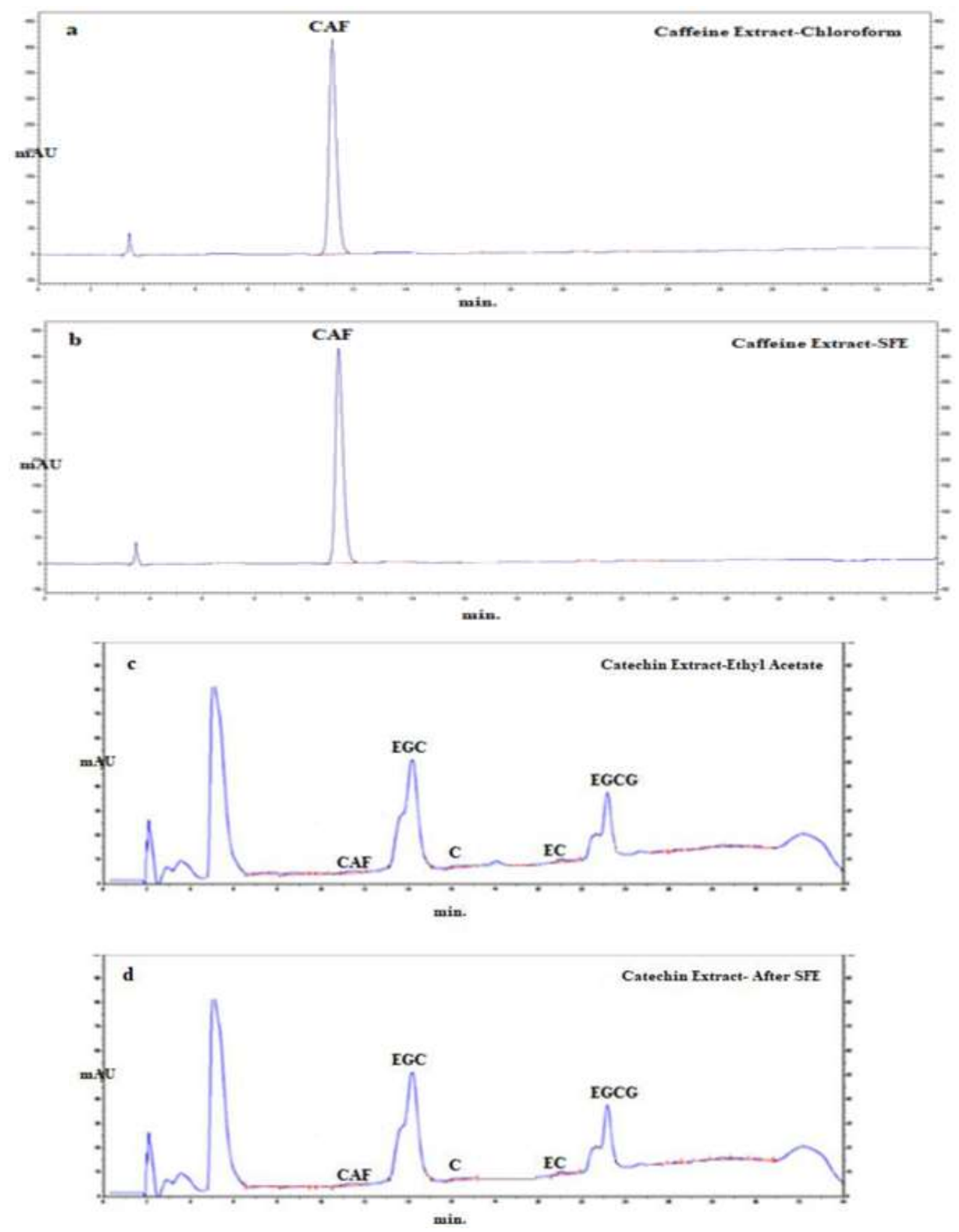

Figure 5. HPLC chromatogram of caffeine and catechin extracts obtained by liquid-liquid extraction (a and c) and SFE (b and d, $25 \mathrm{MPa}, 60^{\circ} \mathrm{C}, 3 \mathrm{~h}$ ) from dried green tea samples initially extracted with MAE. 
The identification of caffeine and catechins were realized by matching their retention times to concerning standards and the amount of individual components was calculated from these chromatograms. Developed SFE method was compared with liquid-liquid extraction method. The purities of caffeine extracts obtained from both methods are given in Figure 5 (a and $b$ ). It is clear that caffeine was successfully removed from the mixture and caffeine extract is pure as much as obtained with liquid-liquid extraction. The composition of catechin extract obtained from the extracting tea infusion with ethyl acetat is given in Figure 5c. Similarly, the composition of catechin extract (a residue after separation of caffeine with SFE) was also determined and given in Figure 5d. Purity and combination of both extract was completely same. The quantitative analysis of each cateshin constituent was determined from HPLC chromatograms. The amount of catechin constituents is given in Figure 6.

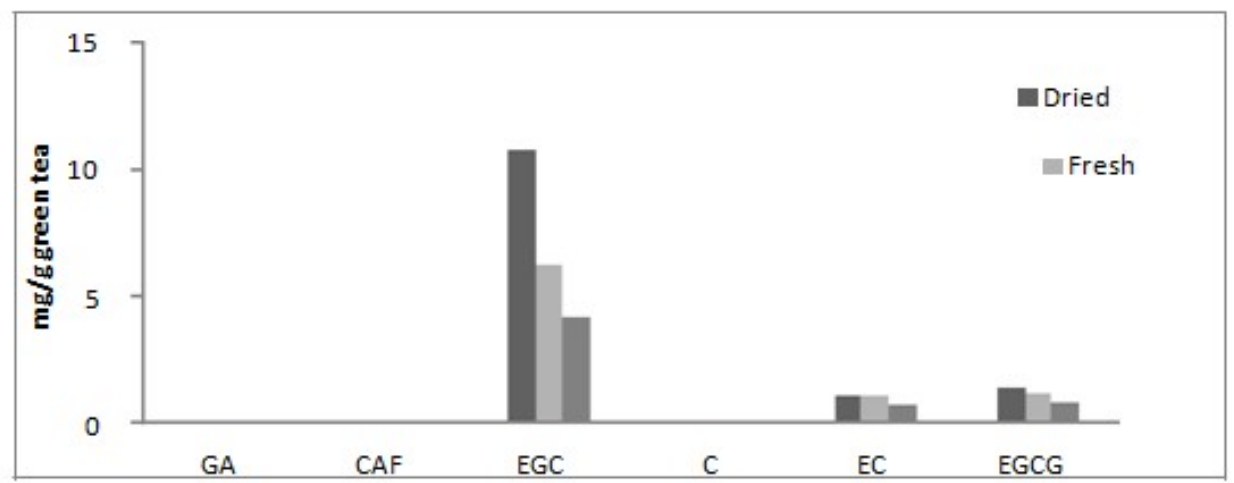

Figure 6. The amount of each cateshin from dried, fresh and frozen using SFE after MAE.

\section{CONCLUSION}

This study provides a practical approach for extraction of green tea bioactive compounds. A lot of methods have been worked for extraction and separation of catechins such as microwave-assisted extraction, maceration, supercritical carbon dioxide extraction. MAE is economical, fast and green extraction method that effective separation of caffeine and catechin from green tea. Both caffeine and catechin extraction was quite successful with microwave assisted extraction following effective separation with SFE. To overcome use of harmful organic solvents, SFE can be a potential method for isolating catechins from the tea leaves. Further search is useful to evolve new methods or the present methods to exceed the limitations of processes. Tea catechins especially EGC and EGCG can be separated from dried, fresh or frozen green tea using green solvents and green technologies in remarkable process periods.

\section{Acknowledgements}

The authors gratefully appreciate the financial support from Turkish Ministry of Industry (SAN-TEZ Project, Grant No 00932.STZ.2011-1) and OrÇay for their financial support.

\section{ORCID}

Gönül SERDAR (Di) https://orcid.org/0000-0002-3589-2323

Münevver SÖKMEN (iD https://orcid.org/0000-0002-7671-4160

\section{REFERENCES}

[1]. Park, H.S., Choi, HK, Lee, S.J., Park, K.W., Choi, S.G., Kim, K.H. (2007). Effect of mass transfer on the removal of caffeine from green tea by supercritical carbon dioxide. $J$. Supercrit. Fluids., 42, 205-2111. 
[2]. Pan, X., Niu, G., Liu, H. (2003). Microwave-assisted extraction of tea polyphenols and tea caffeine from green tea leaves. Chem. Eng. Process, 42, 129-133.

[3]. Stone, M.H., Fleck, S.J., Kraemer, W.J., Triplett N.T. (1991). Health- and performancerelated potential of resistance training. Sports Med., 11, 210-231.

[4]. Chu, D.C. and Juneja, L.R. (1997). General Chemical Composition of Green Tea and Its Infusion. In: Yamamoto, T., Juneja, L.R., Chu, D.C. and Kim, M., Eds., Chemistry and Applications of Green Tea, CRC Press, Boca Raton, 13-22.

[5]. Perva-Uzunalic, A., Skerget, M., Knez, Z., Weinreich, B., Otto, F., Gruner, S. (2006). Extraction of active ingredients from green tea (Camellia sinensis): Extraction efficiency of major catechins and caffeine. Food Chem., 96, 597-605.

[6]. Wang, L., Qin, P., Hu, Y. (2010). Study on the microwave-assisted extraction of polyphenols from tea. Frontiers Chem. Eng., 4, 307-313.

[7]. Gupta, S., Saha, B., Giri, A.K. (2002). Comparative antimutagenic and anticlastogenic effects of green tea and black tea: a review. Muation Res., 512(1), 37-65.

[8]. Kuroda, Y., Hara, Y. (1999). Antimutagenic and anticarcinogenic activity of tea polyphenols. Muation Res., 436(1), 69-97.

[9]. Vuong, Q.V., Roach, P.D. (2013). Caffeine in Green Tea: Its Removal and Isolation. Sep. and Pur. Rev., 43, 155-174

[10]. Sun, Q.L., Hua, S., Ye, J.H., Lu, J.L., Zheng, X.Q., Liang, Y.R. (2010). J. Med. Plants Res., 4(12), 1161-1168.

[11]. Proestos, C., Komaitis, M. (2007). Application of microwave-assisted extraction to the fast extraction of plant phenolic compounds. LWT-Food Sci. and Techn., 41(4), 652-659.

[12]. Zhai, Y.J., Sun, S., Wang, Z.M., Cheng, J.H., Sun, Y.T., Wang, L., Zhang, Y.P., Zhang, H.Q., Yu, A.M. (2009). Microwave extraction of essential oils from dried fruits of illicium verum Hook. f. And Cuminum cyminum L. Using ionic liquid as the microwave absorption medium. J. Sep. Sci., 32, 3544-3549.

[13]. Zheng, J., Huang, Y., Qian, J. (2009). Extraction mechanism study of the microwave cardio-graph (MCG). Mic. Opt. Techn. Letters, 51, 2348-2354.

[14]. Park, H.S., Lee, H.J., Shin, M.H., Lee, K.W., Lee, H., Kim, Y.S., Kim, K.O., Kim, K.H. (2007). Effects of cosolvents on the decaffeination of green tea by supercritical carbon dioxide. Food Chem., 105(3), 1011-1017.

[15]. Lee, S.M., Lee, H.S., Kim, K.H., Kim, K.O. (2009). Sensory Characteristics and Consumer Acceptability of Decaffeinated Green Teas. J. Food Sci., 74,135-141.

[16]. Kim, J.W., Kim, J.D., Kim, J., Oh, S.G., Lee, Y.W. (2008). Selective caffeine removal from green tea using supercritical carbon dioxide extraction. J. Food Eng., 89(3), 303309.

[17]. Büyüktuncel, E. (2012). Gelişmiş Ekstraksiyon Teknikleri. Hacettepe Üniversitesi Eczacılık Fakültesi Dergisi, 32(2), 209-242.

[18]. Bimakr, M., Rahman R.A., Taip F.S., Ganjloo A., Salleh L.M., Selamat J., Hamid A., Zaidul I.S.M.(2011). Comparison of different extraction methods for the extraction of major bioactive flavonoid compounds from spearmint (Mentha spicata L.) leaves. Food Bioprod. Process, 89, 67-72.

[19]. Maran, J.P., Manikandan, S., Priya, B., Gurumoorthi, P. (2013). Box-Behnken Design Based Multi-Response Analysis and Optimization of Supercritical Carbon Dioxide Extraction of Bioactive Flavonoid Compounds from Tea (Camellia Sinensisl.) Leaves. $J$. Food Sci. and Techn., 52(1), 92-104.

[20]. Chang, C.J., Chiu, K.L., Chen, Y.L., Chang, C.Y.(2000). Separation of catechins from green tea using carbon dioxide extraction. Food Chem., 68, 109-113. 
[21]. Pereira, C.G., Angela, M., Meireles, A. (2010). Supercritical fluid extraction of bioactive compounds: fundamentals, applications and economic aspects. Food Bioprocess Technol., 3, 340-372.

[22]. Serdar, G., Demir, E., Bayrak, S., Sökmen, M. (2016). New approaches for effective microwave assisted extraction of caffeine and catechins from green tea. Int. J. Sec. Met., 3, 3-13.

[23]. Serdar, G., Demir, E., Sökmen, M. (2017). Recycling of Tea Waste: Simple and Effective Separation of Caffeine and Catechins by Microwave Assisted Extraction (MAE). Int. J. Sec. Met., 4, 78-89.

[24]. Deng, C.H., Ji, J., Yu, Y.J., Duan, G.L., Zhang, X.M. (2006). Fast determination of curcumol, curdione and germacrone in three species of Curcuma rhizomes by microwaveassisted extraction followed by headspace solid-phase microextraction and gas chromatographymass spectrometry. J. Chromatogr. A., 1117, 115-120.

[25]. Sökmen, M., Demir, E., Alomar, S.Y. (2018). Optimization of sequential supercritical fluid extraction (SFE) of caffeine and catechins from green tea. The J. Supercritical Fluids., 133(1), p.171-176.

[26]. Demir, E. (2015). Isolation of caffeine and cateshins from fresh tea and balck tea waste with different extraction methods. PhD Thesis, The Graduate School of Natural and Applied Sciences, Karadeniz Technical University, Turkey.

[27]. Wang, K., Liu, F., Liu, Z., Huang, J., Xu, Z., Li, Y., Chen, J., Gong, Y., Yang, X. (2011). Comparison of catechins and volatile compounds among different types of tea using high performance liquid chromatograph and gas chromatograph mass spectrometer. Int. J. Food Sci.\& Techol., 46, 1406-1412. 